\title{
An introduction to the Special Issue on "Sports Science: Evolutionary Perspectives and Biological Mechanisms"
}

\section{Davide Ponzi ${ }^{1} \mathbb{D}$}

Received: 19 January 2022 / Revised: 26 January 2022 / Accepted: 27 January 2022 /

Published online: 17 February 2022

(c) The Author(s) 2022

\begin{abstract}
The goal of the special issue on "Sports science: evolutionary perspectives and biological mechanisms" was to build a bridge to help the development of a coherent and unifying approach to the study of sport science within an evolutionary framework. By focusing specifically on the biological and psychological dynamics of sport performance and competition, we asked if sports can be used to study the evolution of human behavior, biology and psychology. Likewise, we asked whether this evolutionary approach could improve our understandings of the physical and psychological limits of human athletic performance and health.
\end{abstract}

Keywords Human evolution · Running economy - Sports science $\cdot$ Trade-offs · Safety factors $\cdot$ Steroids

Can we build a bridge between the disciplines of human evolution and sports sciences such that both disciplines can gain from each other's conceptual and empirical advances? This is the question that motivated this special issue. This interdisciplinary approach is not entirely new, as a recent special issue of Evolutionary Behavioral Sciences on 'Sports, Games, and Athletics in Evolutionary Perspective' (Gallup \& Deaner, 2021) and several publications on evolution and sports performance illustrate (Best 2021; Boullosa \& Nakamura 2013; Calsbeek \& Careau, 2019; Careau, 2017; Careau \& Wilson, 2017a; Halsey and Bryce, 2021; Lombardo \& Deaner, 2018; Manning \& Taylor, 2001; Marino, 2008, 2019; Marino et al., 2004; Longman et al., 2020; Trivers et al., 2013, 2014; Van Damme et al., 2002; Walker \& Caddigan, 2015). Nonetheless, a look at this literature reveals that among these authors there are almost no sports scientists. This is puzzling because both disciplines focus on two important

Davide Ponzi

davide.ponzi@unipr.it

1 Department of Medicine and Surgery, University of Parma, Parma, Italy 
aspects of an organism's behavior: competition and performance. Perhaps there are profound differences in the concepts of competition and performance between these two disciplines that may explain sports scientists' lack of interest in evolutionary theory.

Evolutionary biologists and psychologists are well aware that competition is ubiquitous in nature because accessible resources (food, shelters, mates) are limited in terms of quality and quantity, or because they are costly to acquire (Alexander, 2005). Sports scientists instead focus on ritualized, culturally invented forms of competition that, superficially, look different from those that motivate animals' physical performance in their natural environment.

Likewise, the concept of performance is used in slightly different ways in the two disciplines. Performance can be defined as the ability to carry out a behavior that, if successfully executed, has clear advantages for the performer. For an evolutionary biologist, performance is a measure of evolutionary fitness (Arnold, 1983); in other words, the ability to perform a specific behavior is the result of a long history of selection on those genes (many with complex pleiotropic and epistatic effects) that allowed such behavior to evolve under specific environmental conditions and that led to survival and reproductive success of the bearer and its offspring. For a sports scientist, instead, performance is the observable ability needed to succeed in a competition.

Because sports competition is a human cultural invention, perhaps athletic performance has nothing to do with survival and reproduction (but see Lombardo, 2012) and thus an evolutionary account is of no use in this context. However, both evolutionary biologists and sport scientists would agree that performance represents the result of a complex interaction between the different subsystems that characterize the performing behavior.

Where then are the major differences, if any, between these two disciplines that study competition and performance? Perhaps one of them is that sports scientists are specifically interested in issues of mechanisms (e.g., physiological or cognitive), whereas evolutionary biologists and psychologists are interested in both the proximate and ultimate causes of performance. Proximate and ultimate causes of a behavior refer to two closely related kinds of explanations: the "how does it work" and the "what is it for" questions (Mayr, 1961; Haig, 2013).

By focusing on mechanisms and ontogeny, the first kind of explanation is of common interest for both evolutionary and sports sciences. However, understanding the developmental, physiological or cognitive mechanisms linked to performance begs for the question of why such mechanism came to work in that specific way. Therefore, ultimate questions seek for evolutionary historical and functional-adaptive explanations that require one to accept that a particular trait derives from ancestors or that it is the result of natural selection (Mayr, 1982). Through the integration of these two seemingly different approaches, with this special issue we attempt to build a bridge between evolutionary and sports sciences.

The authors of three of the six articles (Marino, Oliveira-Junior et al.; Villain and Careau) use the concept of tradeoffs to address both functional and mechanistic aspects of human athletic performance. Tradeoffs are ubiquitous in nature and play a central role in evolutionary explanations of human behavior. Since time and 
energy are limited resources, organisms must 'decide' how to allocate them to various activities important to their survival and reproduction. We might expect that fitness-enhancing traits should be positively correlated with one another (higher muscle mass, higher aerobic performance, higher competitiveness and libido in males, for example), but in reality, trade-offs exist such that these positive correlations are not found (Van Noordwijk \& De Jong, 1986).

Addressing this issue, Marino introduces in his article the concept of safety factors, which refers to the relationship between the maximal ability of a system to perform and its actual performance, a concept very similar to that of reserve capacity (Diamond, 2002). The idea here is that traits related to specific performances are designed to have more capacity than expected for their optimal use. This concept may seem counterintuitive. If organisms evolved to respond optimally to specific demands, then why waste time and energy to design traits with more potential than what they actually need? Thus, the presence of safety factors begs for functionaladaptive explanations such as the predictability of "loads" (i.e. ecological pressures such as food shortages, predator or parasite pressures), the "cost of failure", and the cost of maintenance (Diamond, 2002). The presence of safety factors in performancerelated traits highlights how limitation to performance is strictly linked to aspects of evolutionary constraints and of homeostatic regulation, so called evolutionary and proximate level trade-offs (see Garland et al., 2022).

The presence of trade-offs in whole-organism performance has been studied extensively by evolutionary physiologists in several animal models but only recently in humans (Calsbeek \& Careau, 2019; Careau and Wilson, 2017b; Van Damme et al., 2002). A typical trade-off related to locomotor performance is that the best sprinter is rarely also the best endurance runner (Garland, 2014). The importance of studying whole-organism performance trade-offs, especially those related to locomotion, is that performance is directly related to aspects of survival and reproduction and thus to life history traits (Lailvaux and Huske, 2014; Van Damme et al., 2002). Different types of motor actions that rely on the same motor system must be traded-off against each other, giving rise to species and interindividual differences in terms, for example, of endurance vs. speed capacities. Since different species, but also individ,uals within the same species, differ in their composition of skeletal muscles fibers, tradeoffs are expected to exist.

One way to study performance trade-offs is to use elite athletes competing in multi-event sports (van Damme et al., 2002; Calsbeek and Careau 2017). Within athletes of similar tier (who ideally should be comparable in terms of intrinsic and extrinsic factors affecting performance), negative associations between functional groups (running vs. jumping vs. throwing) are expected. In their study, Villain and Careau present evidence for a whole-organism performance trade-off between different swimming strokes in elite swimmers. They used data from 28 years of Olympic individual medley competition and analyzed them with applied multivariate mixed models, a statistical approach that allows for partitioning between- and within- individuals variance on repeated measures (Careau and Wilson, 2017b).

Villain and Careau provide evidence for a negative correlation between backstroke and breaststroke performance in both men and women: those that are better at breaststroke are worse at backstroke. Another interesting finding relates to the sex differ- 
ences in pacing that indicate that individual medley male swimmers do not distribute their pace evenly. While this effect may depend on physical and metabolic differences between male and female athletes that influence their competitive strategies, a similar effect is also observed in different sport competitions such as long distance running, suggesting that an important psychological factor may be at work (Deaner et al., 2015, 2019).

In their review article, Oliveira-Junior and colleagues explore the interesting and important role trade-offs play in skeletal muscle structure and function, especially from a life history perspective. They highlight how the skeletal muscle, being one of the largest and most expensive tissues in the human body, is susceptible to trade-offs in the face of energetic deficits. They describe several variables that can regulate the plastic response of this tissue, such as sex, age, body composition and training status. Skeletal muscle is a tissue with crucial survival and reproductive functions; it plays an important role in predator avoidance and foraging, as well as in fighting and intrasexual competition. These functions are expected to be traded-off depending on species-specific and context-specific factors.

An interesting aspect of this article is Oliveira-Junior and colleagues discussion of the role played by several molecular integrators such as myokines as potential regulatory signalers of life history strategies. Moreover, given the plastic response of skeletal muscle to a series of internal and external signals (nutrition, workload etc.), it would be interesting to integrate the concept of safety factors presented by Marino within the life history perspective presented by Oliveira-Junior et al. For example, starvation affects more type II skeletal muscle fibers, those associated with glycolytic anaerobic power and strength, compared to type I fibers. Yet, there is some evidence from studies with non-human species (e.g., cods) suggesting that despite reduced metabolism and number of glycolytic fibers, sprint performance was maintained in these animals (cited in Lailvaux \& Husak, 2014). Could this effect be a consequence of the higher safety factor of type II fibers?

Another evolutionary concept relevant for sports science is sexual selection, a process that results in the evolution of traits advantageous for mating success, either through the choice of mating partners (intersexual choice) or competition for access to mates (intrasexual competition). Traits that are sexually selected are sexually dimorphic and those that provide an edge over resource competition are often associated with body size, strength, armaments, competitiveness and aggressiveness. The extent of sexual dimorphism shown by a species depends on sex differences in reproductive potential and on the degree to which each sex invests in parenting (Geary, 2010).

Men and women show a number of morphological, physiological and psychological sex differences, ranging from small to large, that are reflected in sex differences in sports performance. On average, men are heavier, taller and have more muscle mass, especially in the upper body (Lassek \& Gaulin, 2009); men have also more oxygen aerobic power and anaerobic capacity (Handelsman et al., 2018) and, tend to show more social dominance (Hines, 2020) and competitiveness (Deaner et al., 2016) compared to women, at least in some contexts.

Sex differences in morphological, physiological and psychological traits associated with sport performance are almost non-existent during childhood but grow and 
become larger as boys and girls go through puberty. Testosterone is a key hormone for the development and maintenance of sexually selected traits and is often identified as one of the mechanisms supporting men's ability to outperform women in sports competitions. Testosterone has pleiotropic effects that are achieved through its anabolic and ergogenic properties (Handelsman et al., 2018), acting from the cellular to the psychological level. Thus, testosterone is associated with more muscle mass, higher hemoglobin levels and also with traits associated with competitiveness such as training motivation (Crewther and Cook, 2018).

In the present issue, Casto et al. describe how baseline levels of this hormone can explain competitive motivation and persistence in women athletes and how testosterone responds acutely to social challenges in athletes compared to non-athletes. Their data, which included salivary samples from 253 young women participating in different sports competitions, training and laboratory tests, are correlational and cannot exclude the possibility that baseline testosterone differences between athletes and non-athletes depend on training and sport participation. Nonetheless, their study highlights how testosterone response is very sensitive to social, competitive challenges in women, as it is in men, possibly underlying an evolved function.

The effects of testosterone on athletic performance in women may suggest that, during the course of human evolution, intrasexual competition has been strong for both males and females. If testosterone's functions are those of shifting physical, metabolic and psychological resources toward competitive contexts, we should expect such mechanism to work effectively also for women. Yet, sexual selection and parental investment theory would suggest that the cost and benefit tradeoffs of direct competition differ between the two sexes leading to the evolution of, for example, social niches within which men and women specialized in different forms of competition (Archer, 2009; Benenson and Abadzi, 2020; Campbell, 1999; Geary, 2010). It is possible then, that in women testosterone is more directly related to forms of indirect aggression and competition instead of more direct and physically costly challenges.

A possible alternative is suggested by the concept of intralocus sexual conflict (Van Doorn, 2009). Intralocus sexual conflict occurs when a trait (morphological or physiological) shared by both sexes is beneficial to one sex but detrimental to the other. In this view, high testosterone may be associated with competition, aggression and status seeking both in males and in females, but it may have higher reproductive costs to women, for example in terms of reduced fertility consequent to (mild) virilization. This hypothesis could explain why among elite female athletes there is a relatively high frequency of individuals with polycystic ovary syndrome (Handelsman et al., 2018).

Human traits important for athletic performance may be important also in contexts other than social competition. For example, there may have been selective pressures leading to the evolution of athletic performance in the context of the physical or ecological environment (for example, for adapting to hot vs. cold climatic conditions), or in the context of foraging behavior, or both (selection for foraging in hot climate conditions). Even if humans may not be an elite endurance species compared to cursory mammals (Halsey and Bryce, 2021), our ability to perform endurance activities during hot periods of the day, along with a set of peculiar traits such as bipedal locomotion, running ability (we are the only primate species with this ability) (Bramble 
\& Lieberman, 2004), hairlessness, eccrine sweat glands (Best \& Kamilar, 2018) and regulation of water balance (Pontzer et al., 2021) beg for an evolutionary explanation (Liebenberg, 2006; Lieberman \& Bramble, 2007; Lieberman, 2012).

An evolutionary perspective could help explain why, for example, there are ethnic differences, especially concerning body size, that affect running performance (Lambert et al., 2008); it may also help us understand the extent to which phenotypic plasticity and its underlying physiological and metabolic mechanisms play an in important role in endurance performance (Longman et al., 2020).

With this in mind, Longman et al. present a study carried out on 46 ultra-endurance runners in which they tested the possibility of a metabolic compensation that would allow athletes of larger body size to maintain high endurance performance. It is known that the metabolic cost of running increases with body size and muscle mass; larger, more muscular athletes are usually better sprinters than endurance runners (Weyand \& Davis, 2005). Running economy depends on ground force generated to support the body and, as pointed out by Longman et al., this force is metabolically costly making larger body size not well suited for long distance running. Yet, the results of their work suggest that individuals of larger size may maintain their ability to perform on long distance running by burning more energy. If this phenomenon is a consequence of phenotypic plasticity, training, or if it reflects an evolved trade-offs remains unclear. But as highlighted by Longman and colleagues, the evolutionary perspective provides the tools to hypothesize and test the possible costs of this adaptability. Lastly, given the recent observations that the men-women performance gap is reduced and possibly reversed in ultra endurance running competitions (Sandbakk et al., 2018), an evolutionary perspective on these sex differences focused on life history trade-offs and their proximate mechanisms is warranted.

Finally, Ponzi et al., make the call for an evolutionary psychobiological approach to the study of sports competition. Their study is based on a small sample of amateur karate fighters for whom they had data on salivary cortisol levels, temperament, and the serotonin transporter linked polymorphic promoter region polymorphism. Their results are suggestive of the possibility that athletic performance could be predicted by a cluster of correlated psychological and physiological traits, in line with the idea that natural selection should favor the co-evolution of traits if their covariation increased performance (and thus fitness).

If modern sport activities are evolutionarily linked to ancestral intraspecific forms of competition, then, they suggest, athletes who succeed in sports may be characterized by a mix of morphological, physiological and psychological traits that provided our ancestors with a performance edge over competitors during fitness-relevant contests. Some of these traits may be related to the ability to deal with the stress of competition. For example, sex differences in athletic performance may be related to differences in responses to competition-related stress. Sex differences in stress responses in men and women have already been documented (Taylor et al., 2000; Stroud et al., 2002). However, this has not been studied in the context of sports activities and from an evolutionary and psychobiological perspective. This may be a very promising area for future research.

The six articles of this special issue certainly do not fully represent all of the different evolutionary concepts and topics that are important to sport scientists, such as 
developmental and phenotypic plasticity, evolutionary mismatch, and evolutionary medicine. However, they provide support to the idea that evolutionary explanations could provide the basis for a deeper understanding of proximate mechanisms related to athletic performance. In order to really understand problems such as the extent of human trainability, biological constraints on athletic performance, human health and human ability to adapt to new challenging environments it may be helpful to consider the evolutionary history of the human phenotypes required for successful sport performance. Building a bridge between evolutionary behavioral science and sports science can also contribute to our understanding of the evolution of human behavior and physiology. The hope is that this special issue will contribute to new studies in this direction.

Data Availability Statement Data sharing not applicable to this article as no datasets were generated or analaysed during the current study.

Conflict of Interest Statement The author declares no conflicts.

Open Access This article is licensed under a Creative Commons Attribution 4.0 International License, which permits use, sharing, adaptation, distribution and reproduction in any medium or format, as long as you give appropriate credit to the original author(s) and the source, provide a link to the Creative Commons licence, and indicate if changes were made. The images or other third party material in this article are included in the article's Creative Commons licence, unless indicated otherwise in a credit line to the material. If material is not included in the article's Creative Commons licence and your intended use is not permitted by statutory regulation or exceeds the permitted use, you will need to obtain permission directly from the copyright holder. To view a copy of this licence, visit http:/creativecommons.org/ licenses/by/4.0/.

\section{References}

Alexander, R. D. (2005). Evolutionary selection and the nature of humanity. Darwinism and philosophy, 301-348

Archer, J. (2009). Does sexual selection explain human sex differences in aggression? Behavioral and brain sciences, 32(3-4), 249-266

Arnold, S. J. (1983). Morphology, performance and fitness. American Zoologist, 23(2), 347-361

Benenson, J. F., \& Abadzi, H. (2020). Contest versus scramble competition: sex differences in the quest for status. Current opinion in psychology, 33, 62-68

Best, A. W. (2021). Why does strength training improve endurance performance? American Journal of Human Biology, 33(6), e23526.

Best, A., \& Kamilar, J. M. (2018). The evolution of eccrine sweat glands in human and nonhuman primates. Journal of human evolution, 117, 33-43

Bramble, D. M., \& Lieberman, D. E. (2004). Endurance running and the evolution of Homo. nature, 432(7015), 345-352

Boullosa, D., \& Nakamura, F. (2013). The evolutionary significance of fatigue. Frontiers in physiology, 4, 309

Calsbeek, R., \& Careau, V. (2019). Survival of the fastest: The multivariate optimization of performance phenotypes. Medicine \& Science in Sports \& Exercise, 51(2)

Campbell, A. (1999). Staying alive: Evolution, culture, and women's intrasexual aggression. Behavioral and brain sciences, 22(2), 203-214

Careau, V. (2017). Energy intake, basal metabolic rate, and within-individual trade-offs in men and women training for a half marathon: A reanalysis. Physiological and Biochemical Zoology, 90(3), 392-398 
Careau, V., \& Wilson, R. S. (2017a). Performance trade-offs and ageing in the 'world's greatest athletes'. Proceedings of the Royal Society B: Biological Sciences, 284(1860), 20171048

Careau, V., \& Wilson, R. S. (2017b). Of uberfleas and krakens: Detecting trade-offs using mixed models. Integrative and comparative biology, 57(2), 362-371

Crewther, B. T., \& Cook, C. J. (2018). A longitudinal analysis of salivary testosterone concentrations and competitiveness in elite and non-elite women athletes. Physiology \& behavior, 188, 157-161

Deaner, R. O., Addona, V., \& Hanley, B. (2019). Risk taking runners slow more in the marathon. Frontiers in psychology, 10, 333

Deaner, R. O., Balish, S. M., \& Lombardo, M. P. (2016). Sex differences in sports interest and motivation: An evolutionary perspective. Evolutionary Behavioral Sciences, 10(2), 73

Deaner, R. O., Carter, R. E., Joyner, M. J., \& Hunter, S. K. (2015). Men are more likely than women to slow in the marathon. Medicine and science in sports and exercise, 47(3), 607

Diamond, J. (2002). Quantitative evolutionary design. The Journal of physiology, 542(2), 337-345

Gallup, A. C., \& Deaner, R. O. (2021). A Darwinian approach to the study of sports, games, and athletics. Evolutionary Behavioral Sciences, 15(2), 89

Garland, T. (2014). Trade-offs. Current Biology, 24(2), R60-R61

Garland, T. Jr., Downs, C. J., \& Ives, A. R. (2022). Trade-Offs (and Constraints) in Organismal Biology. Physiological and Biochemical Zoology, 95(1), 82-112

Geary, D. C. (2010). Male, female: The evolution of human sex differences. American Psychological Association

Haig, D. (2013). Proximate and ultimate causes: How come? and what for? Biology \& Philosophy, 28(5), 781-786

Halsey, L. G., \& Bryce, C. M. (2021). Are humans evolved specialists for running in the heat? Man vs. horse races provide empirical insights. Experimental Physiology, 106(1), 258-268

Handelsman, D. J., Hirschberg, A. L., \& Bermon, S. (2018). Circulating testosterone as the hormonal basis of sex differences in athletic performance. Endocrine reviews, 39(5), 803-829

Hines, M. (2020). Neuroscience and sex/gender: Looking back and forward. Journal of Neuroscience, $40(1), 37-43$

Lailvaux, S. P., \& Husak, J. F. (2014). The life history of whole-organism performance. The Quarterly Review of Biology, 89(4), 285-318

Lambert, M. I., Mann, T., \& Dugas, J. P. (2008). Ethnicity and temperature regulation. Thermoregulation and Human Performance, 53, 104-120

Lassek, W. D., \& Gaulin, S. J. (2009). Costs and benefits of fat-free muscle mass in men: Relationship to mating success, dietary requirements, and native immunity. Evolution and Human Behavior, 30(5), $322-328$

Liebenberg, L. (2006). Persistence hunting by modern hunter-gatherers. Current Anthropology, 47(6), 1017-1026

Lieberman, D. E. (2012). What we can learn about running from barefoot running: An evolutionary medical perspective. Exercise and sport sciences reviews, 40(2), 63-72

Lieberman, D. E., \& Bramble, D. M. (2007). The evolution of marathon running. Sports Medicine, 37(4), $288-290$

Lombardo, M. P. (2012). On the evolution of sport. Evolutionary Psychology, 10(1), 147470491201000101

Lombardo, M. P., \& Deaner, R. O. (2018). Born to throw: The ecological causes that shaped the evolution of throwing in humans. The Quarterly Review of Biology, 93(1), 1-16

Longman, D. P., Wells, J. C., \& Stock, J. T. (2020). Human athletic paleobiology; using sport as a model to investigate human evolutionary adaptation. American Journal of Physical Anthropology, 171, 42-59

Manning, J. T., \& Taylor, R. P. (2001). Second to fourth digit ratio and male ability in sport: Implications for sexual selection in humans. Evolution and human behavior, 22(1), 61-69

Marino, F. E. (2008). The evolutionary basis of thermoregulation and exercise performance. Thermoregulation and Human Performance, 53, 1-13

Marino, F. E. (2019). Human fatigue: Evolution, health and performance. Routledge

Marino, F. E., Lambert, M. I., \& Noakes, T. D. (2004). Superior performance of African runners in warm humid but not in cool environmental conditions. Journal of applied physiology, 96(1), 124-130

Mayr, E. (1961). Cause and effect in biology. Science, 134, 1501-1506. 1963. Animal species and evolution. Cambridge, Belknap Press

Mayr, E. (1982). The growth of biological thought: Diversity, evolution, and inheritance. Harvard University Press 
Pontzer, H., Brown, M. H., Wood, B. M., Raichlen, D. A., Mabulla, A. Z., Harris, J. A. ... Ross, S. R. (2021). Evolution of water conservation in humans. Current Biology, 31(8), 1804-1810

Sandbakk, Ø., Solli, G. S., \& Holmberg, H. C. (2018). Sex differences in world-record performance: The influence of sport discipline and competition duration. International journal of sports physiology and performance, 13(1), 2-8

Stroud, L. R., Salovey, P., \& Epel, E. S. (2002). Sex differences in stress responses: Social rejection versus achievement stress. Biological psychiatry, 52(4), 318-327

Taylor, S. E., Klein, L. C., Lewis, B. P., Gruenewald, T. L., Gurung, R. A., \& Updegraff, J. A. (2000). Biobehavioral responses to stress in females: Tend-and-befriend, not fight-or-flight. Psychological review, 107(3), 411

Trivers, R., Fink, B., Russell, M., McCarty, K., James, B., \& Palestis, B. G. (2014). Lower body symmetry and running performance in elite Jamaican track and field athletes. PloS one, 9(11), e113106

Trivers, R., Palestis, B. G., \& Manning, J. T. (2013). The symmetry of children's knees is linked to their adult sprinting speed and their willingness to sprint in a long-term Jamaican study. PLoS One, 8(8), e72244

Van Damme, R., Wilson, R. S., Vanhooydonck, B., \& Aerts, P. (2002). Performance constraints in decathletes. Nature, 415(6873), 755-756

Van Doorn, G. S. (2009). Intralocus sexual conflict. Annals of the New York Academy of Sciences, 1168(1), $52-71$

Van Noordwijk, A. J., \& de Jong, G. (1986). Acquisition and allocation of resources: Their influence on variation in life history tactics. The American Naturalist, 128(1), 137-142

Walker, J. A., \& Caddigan, S. P. (2015). Performance trade-offs and individual quality in decathletes. Journal of Experimental Biology, 218(22), 3647-3657

Weyand, P. G., \& Davis, J. A. (2005). Running performance has a structural basis. Journal of Experimental Biology, 208(14), 2625-2631

Publisher's Note Springer Nature remains neutral with regard to jurisdictional claims in published maps and institutional affiliations. 